\title{
Comparison of LDL-cholesterol estimated by various formulae with directly measured LDL-cholesterol in a tertiary care centre of Maval Taluka
}

\author{
Mugdha Dilip Garule ${ }^{1}$, Pravin Narayan Baravkar ${ }^{2, *}$, Shilpa Aditya Pratinidhi ${ }^{3}$ \\ ${ }^{1}$ II/III MBBS Student, ${ }^{2}$ Assistant Professor, ${ }^{3}$ Professor and Head, Dept. of Biochemistry, MIMER Medical College, Talegaon \\ Dabhade, Maharashtra, India
}

*Corresponding Author: Pravin Narayan Baravkar

Email: pravinbaravkar.pb@gmail.com

Received: $4^{\text {th }}$ June, 2018

Accepted: $7^{\text {th }}$ August, 2018

\begin{abstract}
Introduction: Low-density Lipoprotein Cholesterol (LDL-C) concentration in blood gives indication of cardiovascular disease risk. LDL-C may vary at various strata of Triglycerides and in metabolic diseases like Diabetes Mellitus. Measurement of LDL-C directly on laboratory instruments is the best method but is costly. It can also be estimated using various formulae. Our study involves the comparison of LDL-C measured directly with LDL-C estimated by calculations using various formulae.

Materials and Methods: Lipid profile data was collected from Central Clinical Laboratory of MIMER Medical College and hospital, Talegaon Dabhade. Serum LDL-C values were estimated by calculation from Triglycerides (TG), Total Cholesterol (TC) and High-density lipoprotein cholesterol (HDL-C) values, using Friedewald's, Cordova and Cordova, Vujovic, Anandaraja, Puavillai, and Hattori formula. Data of Direct LDL-C and LDL-C estimated by various formulae were compared and correlated at various levels of TG.

Result: Puavillai formula correlates the best with Direct LDL-C at TG </= $150 \mathrm{mg} / \mathrm{dL}$. At TG 151-199 mg/dL, Friedewald's formula, while at TG 200-399 mg/dL, Anandaraja formula is the best. At all these TG levels, Puavillai formula correlates the best with Direct LDL-C.

Conclusion: Puavillai formula is the most accurate formula to calculate LDL-C at TG levels up to150 mg/dL and also at all TG levels studied. Friedewald's formula is the best at TG 151 to $199 \mathrm{mg} / \mathrm{dL}$ and Anandaraja formula at TG $200 \mathrm{to} 399 \mathrm{mg} / \mathrm{dL}$ in our study population.
\end{abstract}

Keywords: LDL-cholesterol, Friedewald's formula, Cordova and cordova formula, Vujovic formula, Anandaraja formula, Puavillai formula, Hattori formula.

\section{Introduction}

Lipid profile is a routine blood test done in clinical laboratories. It involves estimation of Triglycerides (TG), Total Cholesterol (TC), High-density Lipoprotein Cholesterol (HDL-C), Low-density Lipoprotein Cholesterol (LDL-C) and Very low density Lipoprotein Cholesterol (VLDL-C) in serum sample. It is useful for screening of abnormalities like hyperlipidemia. LDL-C is an important parameter. Increased LDL-C concentration in blood alarms the risk for cardiovascular disease. ${ }^{1}$

Beta quantification is the method of reference for serum LDL-C measurement. It involves ultracentrifugation technique. The process is not simple to perform. It involves multiple steps. Several direct methods are also available based on selective precipitation. But the sample processing time is long and they are expensive. So the alternative method employed by clinical laboratories is to estimate LDL-C level by calculation. Friedewald's formula is the most commonly used formula. ${ }^{2}$ Results of this formula are good when TG is less than $300 \mathrm{mg} / \mathrm{dL}$. But as TG levels increase above $300 \mathrm{mg} / \mathrm{dL}$, calculated LDL-C values are underestimated, ${ }^{3}$ and at $\mathrm{TG}$ below $150 \mathrm{mg} / \mathrm{dL}$, LDL-C values calculated by using Friedewald's formula are overestimated compared to Directly measured LDL-C values. ${ }^{4}$
LDL Cholesterol can also be calculated using various other formulae. ${ }^{5}$ These are Cordova and Cordova, ${ }^{6}$ Vujovic, ${ }^{7}$ Anandaraja, ${ }^{8}$ Puavillai ${ }^{9}$ and Hattori. ${ }^{10}$ Like Friedewald's formula, these formulae also use TG, TC and HDL-C to calculate LDL-C.

LDL-C may vary at various strata of TG, in metabolic diseases like Diabetes Mellitus, in patients on lipid lowering drugs and also in fasting/ non-fasting samples.

In this study, LDL-C calculated by using different formulae were compared with LDL-C measured directly on biochemistry analyzer over a wide range of TG levels in a population around of MIMER Medical College and hospital-a tertiary care centre in Maval Taluka of Pune district in Maharashtra (India).

\section{Aims and Objectives}

The aim of the study was to compare the estimated values of LDL-Cholesterol (LDL-C) calculated by various formulae with LDL-C estimated by direct method. Direct LDL-C assay in clinical laboratory was based on modified polyvinyl sulfonic acid (PVS) and polyethylene-glycol methyl ether (PEGME) coupled classic precipitation method.

The objective was to collect LDL-Cholesterol values measured directly as well as values of Triglycerides (TG), Total Cholesterol (TC) and HDL- 
Cholesterol (HDL-C) of same patients from the laboratory registers and to estimate LDL-Cholesterol (calculated) with the help of other analytes of lipid profile namely TC, TG \& HDL-C of respective patients by using various formulae: Friedewald's, Cordova and Cordova, Vujovic, Anandaraja, Puavillai and Hattori formula.

\section{Materials and Methods}

This was an observational, retrospective data analysis study. The study was approved by the institutional ethical committee. Data of lipid profile values of two months was collected from Biochemistry OPD laboratory registers available in the Central Clinical Laboratory (CCL) of MIMER Medical College and Dr. B.S.T.R. Hospital, Talegaon Dabhade. Data contained Triglycerides (TG), Total Cholesterol (TC), HDL-Cholesterol (HDL-C) and directly measured LDL-C. After collecting lipid profile data, LDL-C values were calculated from respective TG, TC and HDL-C values by using different formulae as follows (Table 1)

Table 1: Formulae for LDL-C calculation

\begin{tabular}{|l|c|}
\hline \multicolumn{1}{|c|}{ Formula Name } & Formula \\
\hline Friedewald's formula & LDL-C $=$ TC - HDL-C $-(\mathrm{TG} / 5)$ \\
\hline Cordova \& Cordova formula & LDL-C $=3 / 4 \times(\mathrm{TC}-\mathrm{HDL}-\mathrm{C})$ \\
\hline Vujovic formula & LDL-C $=\mathrm{TC}-(\mathrm{TG} / 6.85)-\mathrm{HDL}-\mathrm{C}$ \\
\hline Anandaraja formula & LDL-C $=0.9 \times \mathrm{TC}-(0.9 \times \mathrm{TG} / 5)-28$ \\
\hline Puavillai formula & LDL-C $=\mathrm{TC}-\mathrm{HDL}-\mathrm{C}-(\mathrm{TG} / 6)$ \\
\hline Hattori formula & LDL-C $=0.94 \times \mathrm{TC}-0.94 \times \mathrm{HDL}-\mathrm{C}-0.19 \times \mathrm{TG}$ \\
\hline
\end{tabular}

Data of Directly measured LDL-Cholesterol (Direct LDL-C) and calculated LDL-Cholesterol using various formulae was compared and analyzed at various TG strata: up to $150 \mathrm{mg} / \mathrm{dL}, 151$ to $199 \mathrm{mg} / \mathrm{dL}, 200$ to $399 \mathrm{mg} / \mathrm{dL}$ and more than $399 \mathrm{mg} / \mathrm{dL}$ using correlation coefficient and coefficient of determination by regression analysis with the help of Microsoft Office Excel 2007 (12.0.6787.5000) version for Windows.

\section{Results}

A total 236 lipid profile results were studied. LDL$\mathrm{C}$ values were grouped in different strata of Triglyceride (TG) values according to Adult Treatment Panel III (ATP III) guidelines: $</=150 \mathrm{mg} / \mathrm{dL}(\mathrm{N}=182)$, 151 to $199 \mathrm{mg} / \mathrm{dL}(\mathrm{N}=31), 200$ to $399 \mathrm{mg} / \mathrm{dL}(\mathrm{N}=20)$, $>399 \mathrm{mg} / \mathrm{dL}(\mathrm{N}=3)$. Total number of LDL-C values obtained in these groups is as follows (Table 2)

Table 2: LDL-C values grouped according to different TG levels

\begin{tabular}{|l|c|c|}
\hline Triglycerides (TG) & No. of study subjects & Percentage \\
\hline$</=150 \mathrm{mg} / \mathrm{dL}$ & 182 & $77 \%$ \\
\hline $151-199 \mathrm{mg} / \mathrm{dL}$ & 31 & $13 \%$ \\
\hline $200-399 \mathrm{mg} / \mathrm{dL}$ & 20 & $09 \%$ \\
\hline$>399 \mathrm{mg} / \mathrm{dL}$ & 03 & $01 \%$ \\
\hline Total & 236 & $100 \%$ \\
\hline
\end{tabular}

In stratum of TG values up to $150 \mathrm{mg} / \mathrm{dL}$, values of Direct LDL-C and calculated LDL-C using various formulae showed good correlation. Mean LDL-C value calculated using Puavillai formula (106 mg/dL) was near to mean Direct LDL-C (99.2 $\mathrm{mg} / \mathrm{dL})$.The mean difference observed was $-6.8 \mathrm{mg} / \mathrm{dL}$ and this estimated LDL-C showed the best statistically significant correlation with Direct LDL-C ( $\mathrm{r}^{2}$ 0.8934, p 0.011) (Table 3 \& Fig. 1):

Table 3: LDL-C results by different formulae at TG $</=150 \mathrm{mg} / \mathrm{dL}$

\begin{tabular}{|l|c|c|c|c|}
\hline \multicolumn{1}{|c|}{ Method } & $\begin{array}{c}\text { Mean } \mathbf{\pm} \text { SD } \\
(\mathbf{m g} / \mathbf{d L})\end{array}$ & $\begin{array}{c}\text { Mean difference } \\
(\mathbf{m g} / \mathbf{d L})\end{array}$ & $\begin{array}{c}\text { Coefficient } \\
\left(\mathbf{r}^{\mathbf{2}}\right)\end{array}$ & $\mathbf{p}$ value \\
\hline Direct LDL-C & $99.2 \pm 28.1$ & & & \\
\hline Friedewald's formula & $103 \pm 27.9$ & -3.8 & 0.8933 & 0.097 \\
\hline Cordova \& Cordova formula & $90.6 \pm 22.3$ & 8.6 & 0.8681 & 0.001 \\
\hline Vujovic formula & $107.8 \pm 28.3$ & -8.6 & 0.8926 & 0.002 \\
\hline Anandaraja formula & $101.5 \pm 28.1$ & -2.3 & 0.8612 & 0.222 \\
\hline Puavillai formula & $106 \pm 28.1$ & -6.8 & 0.8934 & 0.011 \\
\hline Hattori formula & $96.7 \pm 26.2$ & 2.5 & 0.8932 & 0.188 \\
\hline
\end{tabular}




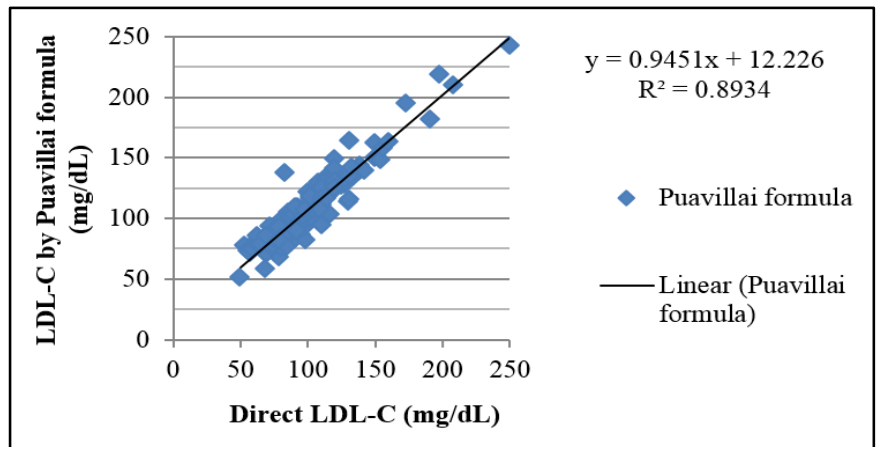

Fig. 1: Comparison of LDL-C estimated by Puavillai formula and direct LDL-C at TG $</=150 \mathrm{mg} / \mathrm{dL}$

At TG stratum of 151 to $199 \mathrm{mg} / \mathrm{dL}$, mean LDL-C calculated using Friedewald's formula showed statistically significant correlation with directly measured LDL-C value, when compared with LDL-C calculated using other formulae. Mean LDL-C estimated by this formula was $106.6 \mathrm{mg} / \mathrm{dL}$. The mean difference between two values was $8 \mathrm{mg} / \mathrm{dL}$ with mean Direct LDL-C value (114.6 mg/dL) ( $\left.\mathrm{r}^{2} 0.7237, \mathrm{p} 0.016\right)$ (Table 4, Fig. 2)

Table 4: LDL-C results by different formulae at TG $151-199 \mathrm{mg} / \mathrm{dL}$

\begin{tabular}{|c|c|c|c|c|}
\hline Method & $\begin{array}{c}\text { Mean } \mathbf{\pm} \text { SD } \\
(\mathbf{m g} / \mathbf{d L})\end{array}$ & $\begin{array}{c}\text { Mean difference } \\
(\mathbf{m g} / \mathbf{d L})\end{array}$ & Coefficient $\left(\mathbf{r}^{\mathbf{2}}\right)$ & $\mathbf{p ~ v a l u e}$ \\
\hline Direct LDL-C & $114.6 \pm 31.5$ & & & \\
\hline Friedewald's formula & $106.6 \pm 33.9$ & 8 & 0.7237 & 0.016 \\
\hline Cordova \& Cordova formula & $106.3 \pm 25.6$ & 8.2 & 0.7048 & 0.007 \\
\hline Vujovic formula & $116.1 \pm 33.9$ & -1.5 & 0.6886 & 0.334 \\
\hline Anandaraja formula & $103.9 \pm 34.1$ & 10.7 & 0.6123 & 0.006 \\
\hline Puavillai formula & $112.5 \pm 33.9$ & 2.1 & 0.6859 & 0.277 \\
\hline Hattori formula & $99.8 \pm 31.9$ & 14.7 & 0.681 & $<0.001$ \\
\hline
\end{tabular}

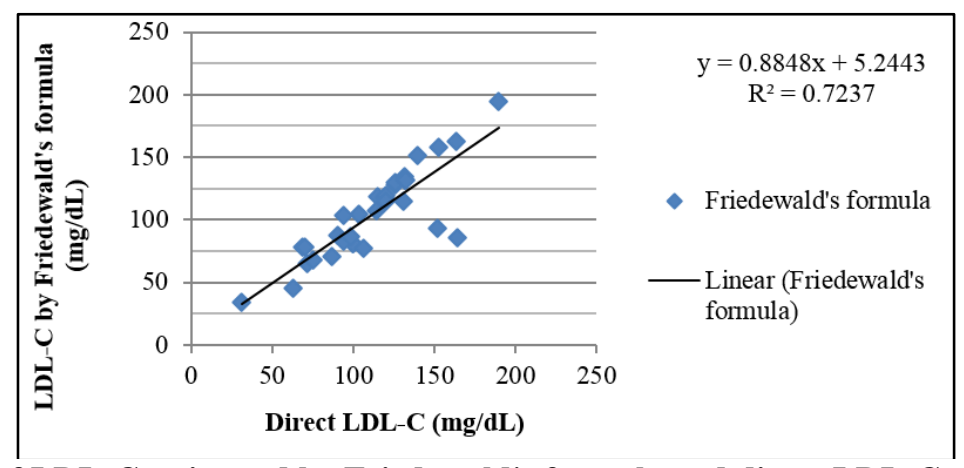

Fig. 2: Comparison of LDL-C estimated by Friedewald's formula and direct LDL-C at TG 151-199 mg/dL

At TG stratum of 200 to $399 \mathrm{mg} / \mathrm{dL}$, mean LDL-C calculated by using Anandaraja formula $(117 \mathrm{mg} / \mathrm{dL})$ showed mean difference of $8.1 \mathrm{mg} / \mathrm{dL}$ when compared with mean LDL-C value measured directly (125.1 $\mathrm{mg} / \mathrm{dL})$. It showed statistically significant correlation than other formulae $\left(\mathrm{r}^{2} 0.7992, \mathrm{p} 0.028\right)$ with mean Direct LDL-C value (Table 5, Fig. 3):

Table 5: LDL-C results by different formulae at TG 200-399 $\mathrm{mg} / \mathrm{dL}$

\begin{tabular}{|l|c|c|c|c|}
\hline \multicolumn{1}{|c|}{ Method } & $\begin{array}{c}\text { Mean } \mathbf{\pm} \text { SD } \\
(\mathbf{m g} / \mathbf{d L})\end{array}$ & $\begin{array}{c}\text { Mean difference } \\
(\mathbf{m g} / \mathbf{d L})\end{array}$ & Coefficient $\left(\mathbf{r}^{2}\right)$ & $\mathbf{p}$ value \\
\hline Direct LDL-C & $125.1 \pm 31.1$ & & & \\
\hline Friedewald's formula & $118.4 \pm 38.1$ & 6.7 & 0.7635 & 0.07 \\
\hline Cordova \& Cordova formula & $125.1 \pm 27.8$ & 0 & 0.6985 & 0.5 \\
\hline Vujovic formula & $131.5 \pm 37.7$ & -6.4 & 0.7519 & 0.077 \\
\hline Anandaraja formula & $117 \pm 37.9$ & 8.1 & 0.7992 & 0.028 \\
\hline Puavillai formula & $126.5 \pm 37.8$ & -1.4 & 0.7568 & 0.371 \\
\hline Hattori formula & $110.9 \pm 35.8$ & 14.2 & 0.7638 & 0.001 \\
\hline
\end{tabular}




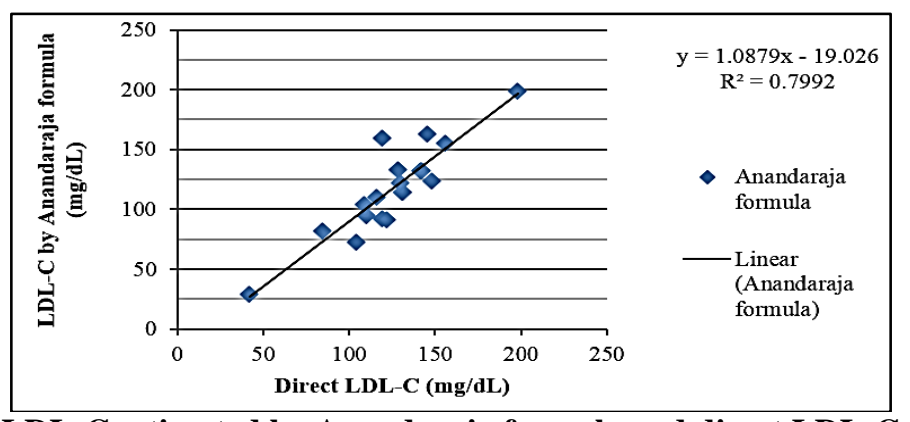

Fig. 3: Comparison of LDL-C estimated by Anandaraja formula and direct LDL-C at TG 200-399 mg/dL

At all above TG levels studied, mean LDL-C calculated by using Puavillai formula $(107.9 \mathrm{mg} / \mathrm{dL})$ showed a mean difference of $-4.8 \mathrm{mg} / \mathrm{dL}$ when compared to mean LDL-C value measured directly
$(103.1 \mathrm{mg} / \mathrm{dL})$. It showed better statistically significant correlation with mean Direct LDL-C value, as compared to other formulae $\left(\mathrm{r}^{2}\right.$ 0.8119, $\left.\mathrm{p}<0.001\right)$ (Table 6):

Table 6: LDL-C results by different formulae at all levels of TG (mg/dL)

\begin{tabular}{|l|c|c|c|c|}
\hline \multicolumn{1}{|c|}{ Method } & $\begin{array}{c}\text { Mean } \mathbf{\pm} \text { SD } \\
(\mathbf{m g} / \mathbf{d L})\end{array}$ & $\begin{array}{c}\text { Mean difference } \\
(\mathbf{m g} / \mathbf{d L})\end{array}$ & Coefficient $\left(\mathbf{r}^{2}\right)$ & p value \\
\hline Direct LDL & $103.1 \pm 29.8$ & & & \\
\hline Friedewald's formula & $104 \pm 30.6$ & -0.9 & 0.7889 & 0.175 \\
\hline Cordova \& Cordova formula & $95.5 \pm 25.5$ & 7.6 & 0.7982 & $<0.001$ \\
\hline Vujovic formula & $110.3 \pm 30.9$ & -7.2 & 0.8215 & $<0.001$ \\
\hline Anandaraja formula & $102.3 \pm 30.6$ & 0.8 & 0.7625 & 0.222 \\
\hline Puavillai formula & $107.9 \pm 30.7$ & -4.8 & 0.8119 & $<0.001$ \\
\hline Hattori formula & $97.5 \pm 28.7$ & 5.6 & 0.7871 & $<0.001$ \\
\hline
\end{tabular}

\section{Discussion}

LDL-Cholesterol concentration in blood has positive correlation with coronary heart diseases like atherosclerosis. This is due to deposition of LDLCholesterol in tissues and endothelial spaces of arteries like coronaries. Hence it is called as bad cholesterol in general terms. As per Adult Treatment Panel III (ATP III), accuracy as well as reproducibility of LDL-C test is very essential.

Direct measurement of LDL-C is accurate but is expensive. For diagnostic laboratories, National Cholesterol Education Programme (NCEP) has recommended widely used Friedewald's formula as a routine method for estimation of LDL-C. But it has certain limitations. At TG level more than $300 \mathrm{mg} / \mathrm{dL}$, Friedewald's formula is not very accurate in calculating LDL-C. ${ }^{7}$ In a study, Ahmadi et al. noted that LDL-C calculation by using Friedewald's formula showed lower values compared to Direct LDL-C values at serum TG more than $400 \mathrm{mg} / \mathrm{dL}$. At low TG levels, calculated LDL-C values were higher than Direct LDL$\mathrm{C}$ values. But at TG between 150 and $300 \mathrm{mg} / \mathrm{dL}$, calculated and Directly measured LDL-C values correlated well. ${ }^{4}$ In our study population, at TG 151 to $199 \mathrm{mg} / \mathrm{dL}$, Friedewald's formula (mean LDL 106.6 $\mathrm{mg} / \mathrm{dL}$ ) showed statistically significant correlation with Direct LDL-C results $(114.6 \mathrm{mg} / \mathrm{dL})$ with a mean difference of $8 \mathrm{mg} / \mathrm{dL}\left(\mathrm{r}^{2} 0.7237, \mathrm{p} 0.016\right)$. But at TG $</=150 \mathrm{mg} / \mathrm{dL}$ and $200-399 \mathrm{mg} / \mathrm{dL}$ it failed to show statistically significant correlation with Direct LDL-C values. Newer formulae offered few advantages over the Friedewald's formula at different TG levels.

Cordova et al. tested a new formula for estimation of LDL-C. The study was conducted in population of Brazil. LDL-C calculated using the formula showed good accuracy and correlated well with LDL-C measured directly. ${ }^{6}$ In our study population, LDL-C calculated using Cordova formula showed fair accuracy with Direct LDL-C values, but did not show statistically significant correlation with mean Direct LDL-C measurements in any of the above studied TG levels.

Vujovic et al. stated in their study that, in Serbian population, formula developed by them for estimation of LDL-C showed better accuracy when compared to Friedewald's formula. ${ }^{7}$ In our study population, Vujovic formula performed well but not the best at different TG levels.

Anandaraja et al. stated a formula for estimation of LDL-C. Formula was tested on Indian population data. They observed that LDL-C calculated using this formula showed good accuracy and correlation with LDL-C measured by direct method. ${ }^{8}$ Also, there was less over estimation of LDL-C values calculated using Anandaraja formula when compared with the values obtained from Friedewald's formula. ${ }^{8}$ Gupta et al. compared results of LDL-C obtained by Friedewald's formula and Anandaraja formula. But they observed that LDL-C estimation error was more when calculated using Anandaraja formula. The results were more erroneous at low total cholesterol and HDL-C values, 
whereas results obtained by Friedewald's formula were better. ${ }^{11}$ In our study population, at TG stratum of 200 to $399 \mathrm{mg} / \mathrm{dL}$, Anandaraja formula showed mean LDL$\mathrm{C}$ value of $117 \mathrm{mg} / \mathrm{dL}$ with a mean difference of 8.1 $\mathrm{mg} / \mathrm{dL}$ with mean Direct LDL-C values $(125.1 \mathrm{mg} / \mathrm{dL})$. At this TG range, the formula showed statistically significant correlation $\left(\mathrm{r}^{2}\right.$ 0.7992, p 0.028) with Direct LDL-C values.

Puavillai et al. made change in Friedewald's formula. It was observed that the original Friedewald's formula showed good accuracy in LDL-C estimation up to $\mathrm{TG}$ level of $200 \mathrm{mg} / \mathrm{dL}$, but not beyond this TG value. As per them, the modified formula developed by them was better in calculating LDL-C in TG stratum of 200 to $499 \mathrm{mg} / \mathrm{dL}$ and it showed a better correlation with Direct LDL-C. ${ }^{9}$ In our study population, Puavillai formula showed good accuracy with statistically significant correlation $\left(\mathrm{r}^{2} 0.8934, \mathrm{P} 0.011\right)$ with Direct LDL-C at TG $</=150 \mathrm{mg} / \mathrm{dL}$. Also, at all above TG levels studied, this formula stood the best in terms of accuracy and correlation with Direct LDL-C values $\left(\mathrm{r}^{2}\right.$ $0.8119, \mathrm{P}<0.001$ )

Formula developed by Hattori et al. does not show better correlation between calculated and directly measured LDL-C values when compared with other formulae in any of the above studied TG groups. ${ }^{10}$

Study conducted by Nishtha Wadhwa et al. concludes that Vujovic formula is more accurate than other formulae in Indian population. ${ }^{12}$ But in our study, LDL-C estimated by Puavillai formula was found to be more accurate \& correlated with directly measured LDL-C in all TG strata studied.

\section{Limitations}

In this study, LDL-C direct assay was used for comparison of LDL-C values instead of reference assay. Sample size is also small; especially at TG more than $399 \mathrm{mg} / \mathrm{dL}$ very less data was available. Hence comparison study in this TG stratum was not possible. Besides this, many formulae for LDL-C estimation other than those studied here are not considered.

\section{Competing Interests: None.}

\section{Funding: None.}

Acknowledgement: We sincerely acknowledge management of MIMER Medical College, Talegaon (D) for their support and encouragement for this work.

\section{Conclusion}

In our study population, Puavillai formula is the best to calculate LDL-C when TG is $</=150 \mathrm{mg} / \mathrm{dL}$. At TG stratum of 151 to $199 \mathrm{mg} / \mathrm{dL}$, Friedewald's formula, while at TG stratum of 200 to $399 \mathrm{mg} / \mathrm{dL}$, Anandaraja formula is the most accurate. At all above TG levels studied, Puavillai formula is the best to calculate LDL-
C. However, more studies using larger sample size are recommended.

\section{References}

1. Keevil JG, Cullen MW, Gangnon R, McBride PE, Stein JH. "Implications of cardiac risk and Low-density lipoprotein cholesterol distributions in the United States for the diagnosis and treatment of dyslipidemia; Data from National Health and Nutrition Examination Survey 1999 to 2002". Circulation. 2007;115:1363-70.

2. T. Cole, C. Ferguson, D. Gibson and W. Nowatzke. "Optimization of quantification methods for high throughput applications”. Clin Chem. 2001;47:712-21.

3. Subramanian Kannan, Shriraam Mahadevan, Bharath Ramji, Muthukumaran Jayapaul and V. Kumaravel. "LDL- Cholesterol: Friedewald calculated versus direct measurement- study from a large Indian laboratory database". Indian J Endocrinol Metab. 2014;18(4):502504.

4. Ahmadi SA, Boroumand MA, Moghaddam KG, Tajik P, Dibaj SA. "The impact of low serum triglycerides on Low-density lipoprotein cholesterol estimation". Arch Iranian Med. 2008;11:318-21.

5. Third Report of the National Cholesterol Education Program (NCEP) Expert Panel on Detection, Evaluation, and Treatment of High Blood Cholesterol in Adults (Adult Treatment Panel III), National Cholesterol Education Program National Heart, Lung, and Blood Institute National Institutes of Health NIH Publication No. 01-3670 May 2001.

6. Cordova CM, Cordova MM. "A new accurate simple formula for LDL-cholesterol estimation based on directly measured lipids from a large cohort". Ann Clin Biochem. 2013;50:13-19.

7. Vujovic A, Kotur-Stevuljevic J, Spasic S, Bujisic N, Martinoric J, Vujovic N. "Evaluation of different formulae for LDLc calculation". Lipids Health Dis. 2010;9:27-35.

8. Anandaraja S, Narang R, Godeswar R, Laksmy R, Talwar KK. "Low-density lipoprotein cholesterol estimation by a new formula in Indian population". Int J Cardiol. 2005;102:117-20.

9. Puavillai W, Laorugpongse D. "Is calculated LDLc by using the new modified Friedewald equation better than the standard Frieldewald equation". J Med Assoc Thai. 2004;87:589-93.

10. Hattori Y, Suzuki M, Tsushima M, Yoshida M, Tokunaga Y, Wang Y, et al. "Development of approximate formula for LDL-cholesterol, LDL-apo B and LDLchol/LDL-apo $\mathrm{B}$ as indices of hyperapobetalipoproteinemia and small dense LDL". Atherosclerosis. 1998;138:289-99.

11. Gupta S, Verma M, Singh K. "Does LDL-C estimation using Anandaraja's Formula give a better agreement with direct LDL-C estimation than the Friedewald's Formula?" Ind J Clin Biochem. 2012;27(2):127-33.

12. Nishtha Wadhwa \& Radhika Krishnaswamy. "Comparison of LDL-Cholesterol Estimate using Various Formulae with Directly Measured LDL-Cholesterol in Indian Population". Journal of Clinical and Diagnostic Research. 2016;10(12):BC11-BC13.

How to cite this article: Garule M.D, Baravkar P. N, Pratinidhi S. A. Comparison of LDL-cholesterol estimated by various formulae with directly measured LDL-cholesterol in a tertiary care centre of Maval Taluka. Int J Clin Biochem Res. 2018;5(4):583-587. 